\title{
Tiempo y memoria en las luchas socioambientales en México
}

\author{
Sergio Tischler y Mina Lorena Navarro
}

\begin{abstract}
A partir del análisis de experiencias de lucha de lo que llamamos movimientos socioambientales, estudiamos el tema de la memoria colectiva como un dispositivo estratégico de resistencia de los sujetos enfrentados a los procesos de despojo territorial como parte de la acumulación de capital en las condiciones actuales de la globalización neoliberal. La memoria, desde esta perspectiva, no es un gesto nostálgico o romántico, sino una manera de resistir que implica, en algunas experiencias, la negación abierta de las expresiones más agresivas y predatorias del capital. En particular, nos importa destacar: a) la resistencia contra el capital; b) el antagonismo social y ciertos rasgos anticapitalistas de su manifestación, y c) la comprensión de estos movimientos como emergencia de una nueva constelación de lucha de clases.
\end{abstract}

PALABRAS CLAVE: memoria, resistencia, antagonismo, capitalismo, subjetividad, constelación, lucha

\section{Time and Memory in Social-Environmental Struggles in Mexico}

Starting from the analysis of struggle experiences by socio-environmental movements, we focus on the theme of collective memory as a strategic device of resistance by subjects confronted with processes of territorial plunder as a part of the accumulation of capital in present conditions of neo-liberal globalization. Memory, from this perspective, is not a nostalgic or romantic gesture but a manner of resisting that implies in some experiences the open denial of the most aggressive and predatory expressions of capital. We are particularly concerned to underline the following themes related with memory and resistance: a) resistance against capital; b) social antagonism and certain anti-capitalist features of its manifestation, and c) the understanding of these movements as the emergence of a new constellation of class struggle.

KEYWORDS: memory, resistance, social antagonism, anticapitalism, struggle class, socio-environmental fights

Sergio Tischler: Instituto de Ciencias Sociales y Humanidades "Alfonso Vélez Pliego", Benemérita Universidad Autónoma de Puebla, Puebla, México sergiovisq@yahoo.com.mx

Mina Lorena Navarro: Doctorado en sociología, Instituto de Ciencias Sociales y Humanidades "Alfonso Vélez Pliego", Benemérita Universidad Autónoma de Puebla, Puebla, México mina.navarro.t@gmail.com

Desacatos, núm. 37, septiembre-diciembre 2011, pp. 67-80

Recepción: 6 de marzo de 2011 / Aceptación: 24 de abril 2011 


\section{LA TIERRA SE DEFIENDE}

$\mathrm{E}$ $\mathrm{n}$ toda la historia de la humanidad, a lo largo $\mathrm{y}$ ancho del planeta han surgido diferentes respuestas sociales para enfrentar la desposesión, el despojo de bienes colectivos, materiales e inmateriales, y la mercantilización general de la vida. No obstante, a partir de los últimos diez años es notoria la emergencia de un nuevo ciclo de luchas socioambientales en América Latina en confrontación abierta con el capital. Esto corresponde en buena parte con el complejo metabolismo de las sociedades capitalistas y su voracidad incesante por expandirse temporal y territorialmente, en principio contra las formas campesinas y populares que han mantenido una relación no predatoria ${ }^{1}$ con el territorio y los bienes comunes.

Nos interesa resaltar uno de los aspectos de los movimientos sociales que luchan contra las políticas de despojo territorial: haber desarrollado una política de la memoria como dispositivo de resistencia, donde ver hacia atrás no es un gesto nostálgico o romántico, sino una manera de ir más allá de las relaciones sociales opresivas, es decir, como parte de un proceso de transformación cuyo punto de partida es la negación de las expresiones más agresivas y predatorias del capital. En las notas que siguen tratamos de hacer una reflexión general al respecto. En particular, nos importa destacar los siguientes temas relacionados con la memoria y la resistencia colectivas: a) la resistencia contra el capital; b) el an-

\footnotetext{
${ }^{1}$ Ana Esther Ceceña (2010) propone, desde una perspectiva histórica de más de 500 años, la identificación de formaciones culturales y su relación con la naturaleza, habiendo por lo menos dos tipos de culturas, que de ninguna manera pueden concebirse como totalmente puras: las no predatorias - afines con la naturaleza, en las que no hay un sujeto único o privilegiado, sino un conjunto de sujetos que interactúan, se complementan y de esa forma van resolviendo sus necesidades-y las predatorias - en las que el sujeto portador es el hombre y la naturaleza está a su servicio, no como otro sujeto sino como objeto-. De estas últimas surge la cultura occidental. Sin embargo, para no dejar la impresión de un sesgo culturalista compartido, agregamos que esas culturas son formas de relaciones sociales y que por "cultura occidental" entendemos la forma capitalista de las relaciones sociales.
}

tagonismo social y ciertos rasgos anticapitalistas de su manifestación, y c) la comprensión de estos movimientos como emergencia de una nueva constelación de lucha de clases.

Sabemos que por lo regular estos temas no aparecen vinculados con el de la memoria colectiva. Sin embargo, proponemos una interpretación que los considera como elemento central de la lucha de clases. Intentamos señalar, de manera todavía balbuceante, lejos de oponerla en abstracto a la forma teórica del conocimiento, la centralidad de la experiencia del antagonismo social en la constitución de una subjetividad crítica al capital. Parte importante de estas reflexiones está teñida del pensamiento de Walter Benjamin. Es necesario indicar que nos referimos a estas luchas como socioambientales porque, desde nuestra perspectiva, son movimientos que se despliegan contra la escisión sociedad-ambiente o sujeto-objeto. La separación entre sociedad y naturaleza ha servido para convertir a esta última en un objeto de dominio, un recurso insertado en el flujo unidimensional del valor y la productividad económica para beneficio del hombre (Leff, 2006: 25).

Recientemente se han conceptualizado las luchas socioambientales como constitutivas de un movimiento global de ecologismo popular o de justicia ambiental (Martínez, 2009: 4) cuya existencia tiene por punto de partida la defensa de los bienes comunes y su reconocimiento como parte intrínseca de la naturaleza, entendida como un sistema de interrelaciones complejo. Este movimiento de justicia ambiental es protagonizado por comunidades y culturas que, enmedio del desgarramiento que han producido las relaciones capitalistas, reafirman sus lazos con la naturaleza y defienden la vida. Estas luchas libran la disputa por la producción y reproducción de la vida, contra el capitalismo, su guerra total y su lógica "anti-vida" (Shiva, 2006: 22) centrada en la ocupación y captura infinita de los procesos vivos.

En México, a partir del acercamiento y trabajo con algunas luchas en defensa del territorio y de los bienes comunes, encontramos elementos compartidos en los modos en los que los cuerpos sociales y 
las subjetividades se organizan y se articulan con las luchas del pasado y habilitan una memoria colectiva, conciben los bienes comunes, enfrentan y resisten la desposesión material e inmaterial de la vida y generan alternativas al capitalismo. Los sujetos colectivos con los que hemos trabajado son la Agrupación Un Salto de Vida, el Consejo de Ejidos y Comunidades Opositores a la Presa La Parota (CECOP) y Radio Ñomndaa de Guerrero, el Consejo de Pueblos Unidos en Defensa del Río Verde (Copudever) de Oaxaca, el Frente de Pueblos de Anáhuac de Tláhuac y el Frente Amplio Opositor de San Luis Potosí. ${ }^{2}$ A continuación planteamos algunas ideas generales sobre la memoria como dispositivo de resistencia en tanto modo de elaboración de una experiencia colectiva enfrentada a la dominación del capital, en la cual se producen umbrales o destellos de formas emancipadas como parte de la lucha contra dicha dominación.

\section{MEMORIA (I): RESISTENCIA}

Nuestra lucha tiene una deuda con nuestros muertos, con nuestros niños.

Marco Suaste, comunero del CEcop. ${ }^{3}$

Antonio Gramsci (1980: 367-381), al plantear el tema de la contradicción entre pensar y hacer en una sociedad definida por el antagonismo de clase, introduce la distinción entre "sentido común" y "núcleo sano de buen sentido" o "buen sentido". Dice

\footnotetext{
${ }^{2}$ En este artículo tratamos de hilar y presentar una serie de testimonios que se desprenden de un amplio número de entrevistas realizadas desde 2008 como parte de una investigación militante sobre las luchas socioambientales como subjetividades críticas al capital. Las experiencias con las que hemos tenido posibilidad de trabajar son el núcleo inspirador de este esfuerzo que busca visibilizar su potencia y lucha digna contra la dominación.

${ }^{3}$ El CECOP es una organización de campesinos y campesinas del municipio de Acapulco, al sur de México, que ha resistido desde hace siete años la construcción de la Presa La Parota sobre el río
}

que en el seno de la ideología dominante o sentido común existe un núcleo de buen sentido que se caracteriza por un tipo fundamental de conocimiento construido por la experiencia de lucha de las clases subalternas. Este conocimiento tiene la potencia de producir una forma de conocimiento coherente, autónomo al del sentido común definido por las clases dominantes, es decir, una coherencia de ninguna manera funcional para la dominación, sino disruptiva. El "núcleo de buen sentido" del sentido común puede ser interpretado, siguiendo la argumentación gramsciana, como una suerte de concepción alternativa embrionaria del mundo surgida de la resistencia a la dominación, esto es, como una forma cultural activa de los de abajo, que entre otras cosas apunta a rechazar la idea de la dominación como un hecho objetivo sin fisuras. Esto nos parece importante. Sin embargo, el paso de esta forma de resistencia a una forma coherente y alternativa al sentido común de la dominación se resuelve en Gramsci por la vía de la hegemonía. Son los "intelectuales orgánicos" (el partido revolucionario como principal figura) los que pueden darle a ese núcleo de buen sentido una coherencia y una forma política universal cuya realización es el Estado. Creemos que se corre un riesgo: subordinar las luchas particulares a una instancia homogeneizante y hegemonizante que puede terminar por romper las formas potenciales de la autonomía de los movimientos anticapitalistas, o de "abajo y a la izquierda", para utilizar la terminología zapatista. Por esa razón preferimos interpretar el espíritu de escisión que hace al "núcleo de buen sentido" desde la perspectiva de la autonomía, la cual, en tanto categoría crítica, implica un proceso de negación de la forma Estado como expresión de

\footnotetext{
Papagayo, impulsada por la Comisión Federal de Electricidad -empresa paraestatal generadora y distribuidora de la energía eléctrica en México-. La construcción de la presa afectaría directamente a 25000 campesinos y desertificaría las tierras de otros 75000 que siembran río abajo. A pesar de que el gobierno federal había anunciado que la construcción de la presa se pospondría hasta 2018, durante los primeros meses de 2010 el gobierno de Guerrero declaró la reactivación del proyecto y con ello las primeras asambleas para operar la expropiación y venta de tierras.
} 
una escisión entre gobernantes y gobernados, característica de las relaciones de dominación. No hay que entender la negación de manera lineal, mecánica e inmediata, sino como un proceso de valoración y potenciación de las formas no estatales de gobierno en las experiencias comunitarias de lucha.

En ese tenor, podemos señalar que en diversas experiencias socioambientales se manifiesta la emergencia de una tendencia a rechazar no sólo los canales y estructuras formales que constituyen la relación mando-obediencia positivizados por las reglas estatales para contener la participación y la rebeldía, sino cualquier estructura que intente capturar o subordinar su autonomía, entendida como la capacidad colectiva para intervenir en el asunto común y definir sus propios fines y modos para lograrlos (Gutiérrez, 2009). Esto se puede percibir, por ejemplo, en los testimonios de integrantes del CECOP del estado de Guerrero. Dicen al respecto:

[Desde que comenzó la lucha contra la presa] cambiaron muchas cosas, porque los líderes que estaban en la zona a hoy no pueden entrar. Son rechazados, les quitamos el poder que tenían [...]. Hemos tratado de quitar la frase "líder", hoy tratamos de cambiarla por "representantes" de comunidades o "voceros" pero ya quitar esa frase de líder [...] acá queremos que haya representantes de pueblo que defiendan a su pueblo, no que se beneficien de él, y que trabajen para su pueblo. Y ellos se aprovechaban del pueblo para beneficiarse (entrevista a Felipe Flores).

Otra cuestión es que en todo momento el CECOP se dio cuenta de que hay movimientos en los cuales se van montando las ONGs, y al rato ellas son las que van tomando las determinaciones y en el caso del CECOP se dijo "adelante todas las ongs, pero aquí decidimos nosotros" (entrevista a Rodolfo Chávez).

En otras experiencias estudiadas se presentan testimonios similares, como las de la Agrupación Un Salto de Vida, del Frente de Pueblos en Defensa de la Tierra de Puebla Tlaxcala-Región Ixta-Popo, del Comité Salvemos Temacapulín, de Radio Ñomndaa, el Consejo de Pueblos Unidos en Defensa del Río Verde o del Frente de Pueblos de Anáhuac.
Es una cuestión de peso. En buena parte de la corriente ortodoxa del marxismo el tema de la subjetividad revolucionaria es trabajado de manera jerárquica, siguiendo la tradición iluminista: en la cúspide de la jerarquía se encuentra el concepto teórico. De tal suerte, para que una acción sea revolucionaria debe estar necesariamente mediada por la teoría revolucionaria, lo cual restringe de modo superlativo la noción de los sujetos en lucha para producir autónomamente acciones auténticamente disruptivas y revolucionarias. Otra perspectiva es plantear que, en el mejor de los casos, la teoría y la organización revolucionaria pueden potenciar las luchas de los sujetos en lucha, no porque la ciencia o la razón las definan sino porque, como sugiere Walter Benjamin (2007), el concepto revolucionario es parte de la tradición de la resistencia de los explotados. Las ideas teóricas potencian la lucha precisamente porque son parte de la experiencia, en este caso de la experiencia de resistencia, lo que habla de la relación interna de complementariedad y diferencia entre un aspecto y otro, en que ambos términos se median mutuamente. ${ }^{4}$ En otras palabras, la unidad entre el concepto y la experiencia no se consigue a costa de la subordinación de la experiencia al concepto, lo cual sería una unidad represiva impuesta por este último, es decir, por la abstracción. ${ }^{5}$ Esa relación implica la retención de la particularidad de las luchas y de los sujetos, pero sin fetichizarla, esto es, sin transformarla en un fin en sí mismo sin relación con la totalidad. Queremos destacar que la producción de conocimiento crítico no es algo exclusivo de la ciencia o de la teoría, sino que tiene un campo fundamental de elaboración en la resistencia de los colectivos populares, y cuando la teoría es crítica reconoce en ese flujo colectivo su fuente.

\footnotetext{
${ }^{4}$ Sobre este aspecto de la praxis véase Adorno (1975).

${ }^{5} \mathrm{La}$ abstracción no vive en el aire o la cabeza de un pensador. La abstracción a la que hacemos referencia es real-material y se despliega en formas institucionales y organizativas que son el resultado y la expresión de la escisión entre trabajo intelectual y trabajo manual que impone la relación capitalista. Véase Sohn (2001).
} 


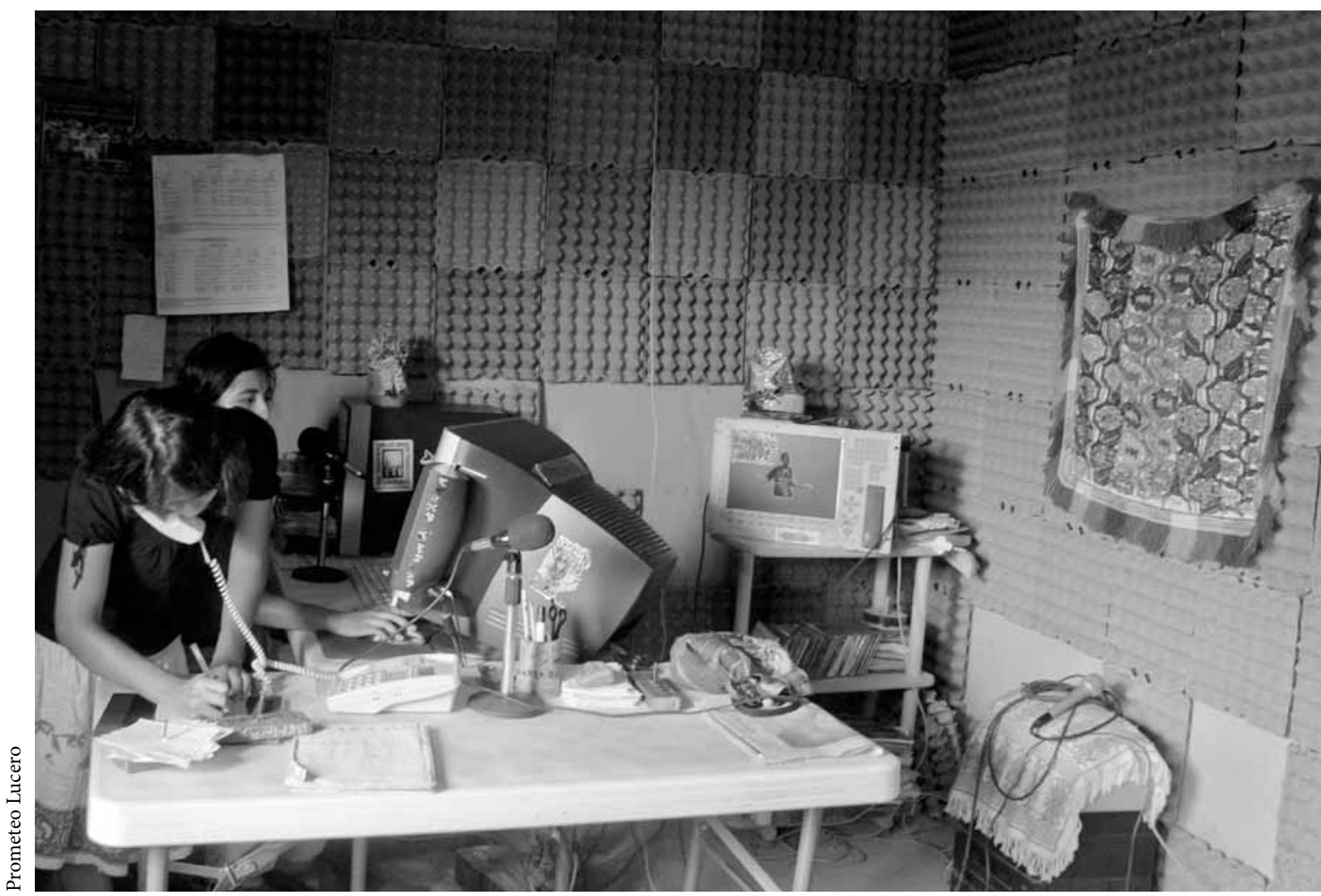

Cabina de locución de Radio Ñomndaa, 2010.

Retomando el tema con las acotaciones planteadas, se podría decir que la memoria colectiva es parte del "núcleo de buen sentido" de las comunidades y grupos socioambientales, y que éste se constituye del recuerdo desde el presente (en el aquí y ahora de la lucha) con las luchas pasadas. La memoria como ejercicio colectivo de apropiación del pasado habilitada por la lucha presente alcanza a reconocerse en el testimonio de un integrante del ya citado CECOP del estado de Guerrero:

Estoy orgulloso de haber nacido en Cahuatepec, nosotros tenemos historia, nosotros descendimos de los indios chopes. Era un pueblo rebelde, y por eso aquí La Parota tiene parte de esta genética, un pueblo rebelde que nunca se ha dejado del gobierno.

Yo los invito a que se sumen a esta lucha tan noble, que surgió con la esperanza de cuidar la riqueza de nuestros antepasados. Los españoles se robaron nuestro oro, a cambio de espejitos regalábamos barras y riquezas, ahora después de tantos años la única riqueza que nos queda es el agua y la tierra, la naturaleza. Que para nosotros significa todo, engloba una serie de sentimientos que para nosotros es invaluable (entrevista a Marco Suaste).

Como se puede apreciar en dicho testimonio y en otros estudiados aquí, la memoria le confiere profundidad a la lucha. Ya no es sólo el enfrentamiento por una reivindicación determinada, sino una lucha en la que se ponen en movimiento las generaciones del pasado, sus logros, esperanzas y fracasos. Este giro permite la elaboración de la conciencia en la que la comunidad es algo más que individuos con intereses comunes inmediatos. La comunidad es también una relación con los antepasados, tiene la profundidad del tiempo de los muertos, un tiempo traducido en lealtades y esperanzas. Sin duda, algo 
retórico para una mirada pragmática y positivista, pero no así para las comunidades en lucha.

La memoria se presenta como un principio esperanza que guarda en su núcleo el sentido y la idea de un futuro que no es prolongación lineal y mecánica del presente, sino una escisión que implica la temporalidad del futuro en el presente de la lucha. Ese tiempo nuevo, en tanto potencia en marcha, surge cuando se habilitan ciertas capacidades prefigurativas colectivas como parte del enfrentamiento con el capital. Éstas pueden ser entendidas como "un conjunto de prácticas que, en el momento presente, 'anticipan' los gérmenes de la sociedad futura" (Ouviña, 2007: 180), en contra de un futuro fijado por el peso opresivo del progreso. Como dicen los zapatistas: "Es importante resistir, pero también es importante construir el mundo que queremos aquí y ahora".

Veamos este asunto a partir del tema de la tierra y el despojo. Se sabe que para las grandes empresas detrás de los megaproyectos, o en términos más generales para el capital, la tierra y la naturaleza son objetos para ser usados en función de la producción de lucro, de beneficio capitalista, en tanto aglomerado de recursos naturales. En otras palabras, la tierra y la naturaleza, como mercancías, están subsumidas a la dinámica de la valorización del capital. En este metabolismo social las cualidades insustituibles de los bienes naturales se encuentran en proceso creciente de subordinación a la lógica del equivalente general - dinero-, es decir, al proceso de abstracción de las cualidades específicas de las distintas mercancías, o abstracción real. Para las empresas, como expresión particular del capital, la cuestión de la tierra y la naturaleza se reduce a dinero, y el dinero en tanto forma del capital, a posibilidad de uso y explotación de fuerza de trabajo que produce más valor que su propio valor como mercancía: una relación puramente instrumental con la naturaleza. Si el metabolismo del capital es un proceso de reducción de la naturaleza a dinero, el uso instrumental de la misma nos habla de una forma destructiva de la relación social. El consumo productivo de la naturaleza en términos de la valorización es sinónimo de destrucción y catástrofe. Esto queda fuera del horizonte abstracto de la ganancia, aunque las consecuencias concretas sean desastrosas. De tal modo que, lejos de concebir la catástrofe ambiental como parte inherente del metabolismo de la sociedad capitalista, se explica como simple externalidad o fallo del mercado, como efecto negativo no recogido en los precios del mercado por su carácter excepcional (Martínez, 2009: 1).

Para las comunidades en resistencia contra el despojo agrario de los megaproyectos el asunto es diferente. La tierra, los bosques y los ríos no tienen precio, por eso el término "despojo". Como dice Shiva (2006: 70), "desde la perspectiva de los poderosos, el cercamiento a los espacios comunales trae progreso, desarrollo y crecimiento. Desde la perspectiva del pueblo llano, los cercamientos acarrean más pobreza e impotencia, hasta el punto de convertir en prescindibles a muchas personas". Para los poderosos esto es desarrollo y dinero, para los pueblos es muerte y aniquilamiento. $\mathrm{Al}$ respecto, recuperamos el testimonio de un integrante de la Coordinación de la Radio Nomndaa: ${ }^{6}$

Es posible construir otras relaciones, no solamente entre personas [...] sino también cómo convivimos con la tierra, con los árboles, con la naturaleza misma, que nosotros mismos decimos la "madre tierra". Entonces vemos que en el sistema capitalista todo lo ven como mercancía, todo lo quieren comprar y vender, pero en realidad si lo vemos así vamos a una muerte segura de nuestros pueblos, de la vida misma (entrevista a David Valtierra).

Para esos campesinos y pobladores en resistencia, la tierra y los bienes naturales son una parte fundamental

\footnotetext{
${ }^{6}$ Radio Nomndaa es un proyecto de comunicación y organización a cargo de comunidades indígenas del pueblo amuzgo en la Costa Chica de Guerrero. Desde 2002 impulsa un proceso profundo de construcción de autonomía en esa zona. Además, desde hace por lo menos diez años ha estado involucrada en la defensa de sus bosques contra la explotación maderera y recientemente es parte de una lucha contra el saqueo de la grava de los ríos de sus comunidades, emprendida por las autoridades municipales y la cacique de la zona, Aceadeth Rocha.
} 
de la comunidad. Por un lado, el metabolismo social campesino implica una relación de naturaleza no instrumental de complementariedad y reciprocidad con la "madre tierra", no sometida al cálculo y al beneficio. Para ellos, la tierra no es un objeto como lo es para el mercado y la ciencia positiva. Por otro lado, la tierra es el territorio profundo de las generaciones pasadas, un espacio habitado por el tiempo de la comunidad, es decir, en esas experiencias sin tierra no hay comunidad. La comunidad no está definida centralmente por la idea de nación o de "comunidad imaginada" (Anderson, 1993) en el sentido clásico que propone una suerte de restauración imaginaria del vínculo colectivo como mediación del desgarramiento social que supone el "individualismo posesivo" (Macpherson, 1979) y la abstracción respecto de la forma comunitaria del ethos campesino. ${ }^{7}$ Como dice Valtierra: "Lo principal es defender el territorio. Si no tenemos el territorio, perdemos todo, perdemos todo. Eso es lo más importante ahorita. Detener el despojo, la explotación del territorio..." (entrevista a David Valtierra).

Se puede decir que la tierra y la naturaleza son parte de la memoria de la comunidad. Esa memoria es una lucha por la preservación de la tierra y la naturaleza como herencia colectiva y requiere poner en movimiento todo su saber acumulado y su astucia (Ceceña, 2008: 106) para emerger y, sobre todo, para rebelarse contra el poder. Dicha memoria, como tiempo profundo de la comunidad, no es un hecho aislado. Este componente de los movimientos socioambientales es parte de un flujo de resistencia mucho más amplio: la memoria indígena y campesina que late desde lo más subterráneo de la historia de los de abajo. ${ }^{8}$

\footnotetext{
7 Ésta es una cuestión importante particularmente en México, donde la representación moderna de la nación como "comunidad imaginada" surgió de un proceso revolucionario en el que el campesinado fue una fuerza central. Dicha representación incluye trazos de la forma campesina en lo nacional-popular, todavía fuertes pese a los esfuerzos de la tecnocracia neoliberal por esfumarlos.

${ }^{8}$ En las experiencias socioambientales indígenas y campesinas con las que hemos trabajado ha sido mucho más visible el ejercicio de articulación de la memoria como tiempo profundo de la
}

México es un país de profunda memoria campesina a pesar de la implementación de las políticas neoliberales que ha provocado el desmantelamiento del campo y de esa memoria. En la actualidad, el entramado de las unidades productivas campesinas enfrenta la peor de las crisis. La alta migración de la población rural hacia las ciudades y Estados Unidos, la dependencia alimentaria, la destrucción de las culturas y tejidos comunitarios, el despojo de tierras a partir de la cesión de derechos a particulares y, en general, la pulverización de la producción agrícola campesina a nivel nacional son algunos de los componentes de esta crisis. En este contexto, el levantamiento zapatista fue fundamental para que la memoria indígena y campesina irrumpiera radicalmente en el ámbito nacional para establecer nuevos horizontes y sensibilidades políticas. Ese México se proyecta en la visión de país, por eso puede decirse que la memoria de los pueblos en lucha, incluyendo los movimientos socioambientales contra el despojo, no es un pasado-pasado sino un pasado-presente, movilizado como horizonte de esperanza. De la historia profunda emerge la memoria como dispositivo de resistencia, en defensa de la vida y contra el despojo de futuro. Como dice Valtierra en su testimonio:

\begin{abstract}
el hecho de darnos cuenta de nuestra historia de antes y de cómo es la historia reciente, uno se va dando cuenta contra qué estamos luchando. Antes nosotros decíamos, nuestros abuelos decían que Dios nos dio esta suerte de vivir de esta manera, pero hay otros que dicen que nosotros vivíamos diferentes, antes éramos más libres. Entonces tener esta memoria histórica, de cómo eran los tiempos antes del sometimiento, y cómo son las cosas ahora. Y por eso a nosotros nos entra el coraje, la rebeldía de por qué vamos a vivir así, vamos a seguir la lucha de nuestros abuelos, de los que no se dieron por vencidos, que nos han dado la oportunidad de tener un territorio (entrevista a David Valtierra).
\end{abstract}

comunidad. No obstante, hay otras experiencias del ámbito urbano, como el caso de la Agrupación Un Salto de Vida, en el que la memoria ha sido fundamental como un recurso movilizador de la lucha de la comunidad contra la contaminación del río Santiago. 


\section{MEMORIA (II):ANTAGONISMOY ANTICAPITALISMO}

¿Formaciones premodernas que se oponen al progreso? ¿Resabios del pasado que no quieren morir? Más bien, las luchas indígenas y campesinas y los movimientos socioambientales son un componente central del antagonismo social en la actualidad. Eso no quiere decir que el capitalismo no haya sido históricamente antagónico al campesinado y a los indígenas, baste con recordar la llamada acumulación originaria de capital, la conquista y el colonialismo en estas tierras americanas. De hecho, el capitalismo, desde su surgimiento, ha significado una guerra permanente contra el campesinado y las poblaciones indígenas. La acumulación de capital no necesita solamente de la transformación de los trabajadores en vendedores de fuerza de trabajo, sino de la apropiación territorial. La tendencia del capitalismo es integrar todos los territorios que han estado al margen del desarrollo capitalista para "crear nuevos espacios te, esto ha implicado la violenta destrucción de antiguas matrices civilizatorias y la integración de productores que antes eran autónomos (Gilly y Roux, 2009), además de millones de historias de ultraje, saqueo, muerte, desconcierto y tristeza en todo el planeta (Ceceña, 2008: 37).

Vastas extensiones territoriales que en décadas pasadas estaban fuera del mapa estratégico de inversión del capital en el corto plazo son ahora consideradas de importancia primordial para la reproducción del sistema. En esas condiciones, el campesinado, la población indígena y las culturas no predatorias en general (Ceceña, 2010) están sufriendo una embestida brutal por parte del Estado y de las corporaciones privadas. No es algo nuevo, pero plantea para estos sectores una situación de urgencia excepcional porque, entre otras cosas, aparece en el horizonte la posibilidad de su desaparición y exterminio. Los problemas que enfrentan estas luchas están atravesados por el tiempo de la urgencia, se sitúan en el umbral entre la vida y la muerte, entre la vida y la nada

(Regalado, en prensa). Aquí es donde aparece el factor tiempo como un componente muy explosivo. Es sabido que la crisis económica del campo y sus efectos sociales en el campesinado y los indígenas tiene una larga data, pero las políticas actuales no sólo han agudizado la crisis, sino que han generado las condiciones para que las estrategias de despojo sean posibles, como explica Rodolfo Chávez del cecop:

Desde que entró el neoliberalismo es más fácil importar que producir y eso causó un desastre. En el caso de los megaproyectos, a propósito descuidaron el campo para que esos lugares no recibieran ninguna ayuda, para que dijera el gobierno son tierras improductivas, entonces hay que quitárselas. En este caso es el gobierno, pero en otros megaproyectos son las empresas trasnacionales (entrevista a Rodolfo Chávez).

Esto crea una situación de enfrentamiento y violencia entre los sujetos colectivos afectados por las políticas de acumulación capitalista y los agentes de las mismas - el Estado y las empresas privadas, fundamentalmente-. Para los sujetos colectivos que rechazan esas políticas pareciera ser que la consigna es no desaparecer. Los movimientos socioambientales, como luchas ancladas a un territorio, a un tejido comunitario y a los tiempos y espacios de la vida diaria, enfrentan cambios dramáticos en su vida cotidiana con las citadas políticas de despojo. La vivencia del antagonismo, experimentado como dolor cotidiano, como injusticia, ha dado lugar a la elaboración de la memoria colectiva como un tipo específico de conciencia de la contradicción entre comunidad y capitalismo. Las palabras de una de las integrantes de la Agrupación Un Salto de Vida en Jalisco, quienes enfrentan una alarmante situación

\footnotetext{
${ }^{9}$ La Agrupación Un Salto de Vida es una organización territorial-comunitaria de vecinos de El Salto, Zona Metropolitana de Guadalajara, Jalisco, que se reúne desde mediados de los años noventa para emprender acciones contra los efectos a la salud y daños ambientales que la contaminación del río Santiago ha generado desde la década de los setenta por las descargas residuales e industriales que se arrojan en su cauce.
} 
de desastre ambiental por la contaminación del río Santiago, ubicado a metros de sus viviendas, revelan este dolor cotidiano como antagonismo y grito contra la dominación:

Hay algo que está lastimando a la gente. Es la salud. Si de algo tenemos miedo es de la muerte, si hay algo que no está atendiéndose es eso. Eso nos lleva al conflicto interno, personal, colectivo, comunitario. ¿Te quedas? ¿A qué te quedas? ¿Te vas? Entonces ya no ayudas, ya no aportas, ya no resistes, pero si te quedas corres el riesgo de morir, por estar expuesto. Es una muy fuerte contradicción que todavía no hemos podido darle salida [...] El olor anoche que estaba muy fuerte, me da mucha tos, y yo pensaba: "Me quedo, no le hace que me muera", pero si me voy "ya no voy a tener la fuerza para seguir en esto" (entrevista a Graciela y Enrique Enciso, 2010).

La contradicción entre comunidad, colectivos populares y capital, más que en formulaciones abstractas, aparece en el lenguaje de las imágenes. Hay que decir que ciertas claves de un lenguaje crítico de naturaleza conceptual - por ejemplo, la palabra "capital" como nombre de una relación destructiva - también entran en la elaboración de esa memoria, pero la mayoría de las veces las imágenes recogen la forma antagónica en que se percibe el mundo del capital. Frente a la naturaleza y la colectividad, el capital se muestra como una máquina destructiva y sin alma, negadora de un horizonte humano ${ }^{10}$ y el asunto de la democracia se vincula a este tema:

La democracia se construye a partir del dinero y de las promesas, utilizar la pobreza de la gente para llegar a un poder y mantener a la gente en esa pobreza. Quien tiene dinero es quien puede llegar a ser presidente, es el que está encima de los demás, es el que es respetable, es el triunfador. La sociedad capitalista da más valor a esa persona (entrevista a David Valtierra).

\footnotetext{
${ }^{10}$ A partir de ese eje del antagonismo, la resistencia puede adquirir una connotación más radical, con trazos y contenidos de anticapitalismo. En las condiciones señaladas, la lucha contra el despojo y la defensa de los bienes comunes es un modo de negación de la forma temporal-espacial de la reproducción capitalista.
}

La radicalidad de estas luchas se profundiza, en tanto que la resistencia va cuestionando no sólo los procedimientos y la exclusión de las decisiones, sino el porqué y el para qué de estos proyectos de "desarrollo" y explotación de los recursos (Navarro y Pineda, 2009: 95). De aquí que los lenguajes de valoración no capitalistas emerjan y se fortalezcan.

\begin{abstract}
Mientras que nosotros sigamos siendo parte del sistema capitalista, siendo parte de los procesos, dándole fuerza al sistema, pues lejos va a estar el camino que necesitamos. Difícil, pero hay que plantear otra manera de luchar. [...] ser parte del sistema es buscar una posición dentro del sistema mismo. Con las instancias, así como están ahora, no es posible construir los cambios que nosotros necesitamos, es más como una manera de entretenernos o de absorbernos la rebeldía (entrevista a David Valtierra).
\end{abstract}

Es necesario subrayar el impacto que ha tenido el zapatismo en los movimientos campesinos e indígenas, en particular en este ciclo de luchas socioambientales emergentes. La lucha zapatista articula en una política de la memoria la idea de un tiempo presente que es lucha anticapitalista, en que los antepasados tienen un lugar central y activo - como pasado-presente-, así como las nuevas generaciones. De allí el énfasis en el sistema de educación autónomo. La autonomía es parte de ese proceso.

\section{MEMORIA (III): CONFORMACIÓN DE UNA NUEVA CONSTELACIÓN DE LUCHA DE CLASES}

Como fue planteado, las luchas de los pueblos indígenas y campesinos, en específico las luchas de carácter socioambiental, son parte de una relación antagónica con el capital, lo cual se expresa a partir de distintas estrategias de resistencia como enfrentamiento práctico e inmediato al poder. Puede observarse con claridad que existe una lucha del capital por imponer su ley y, por otro lado, una resistencia de los sujetos colectivos para preservarse 


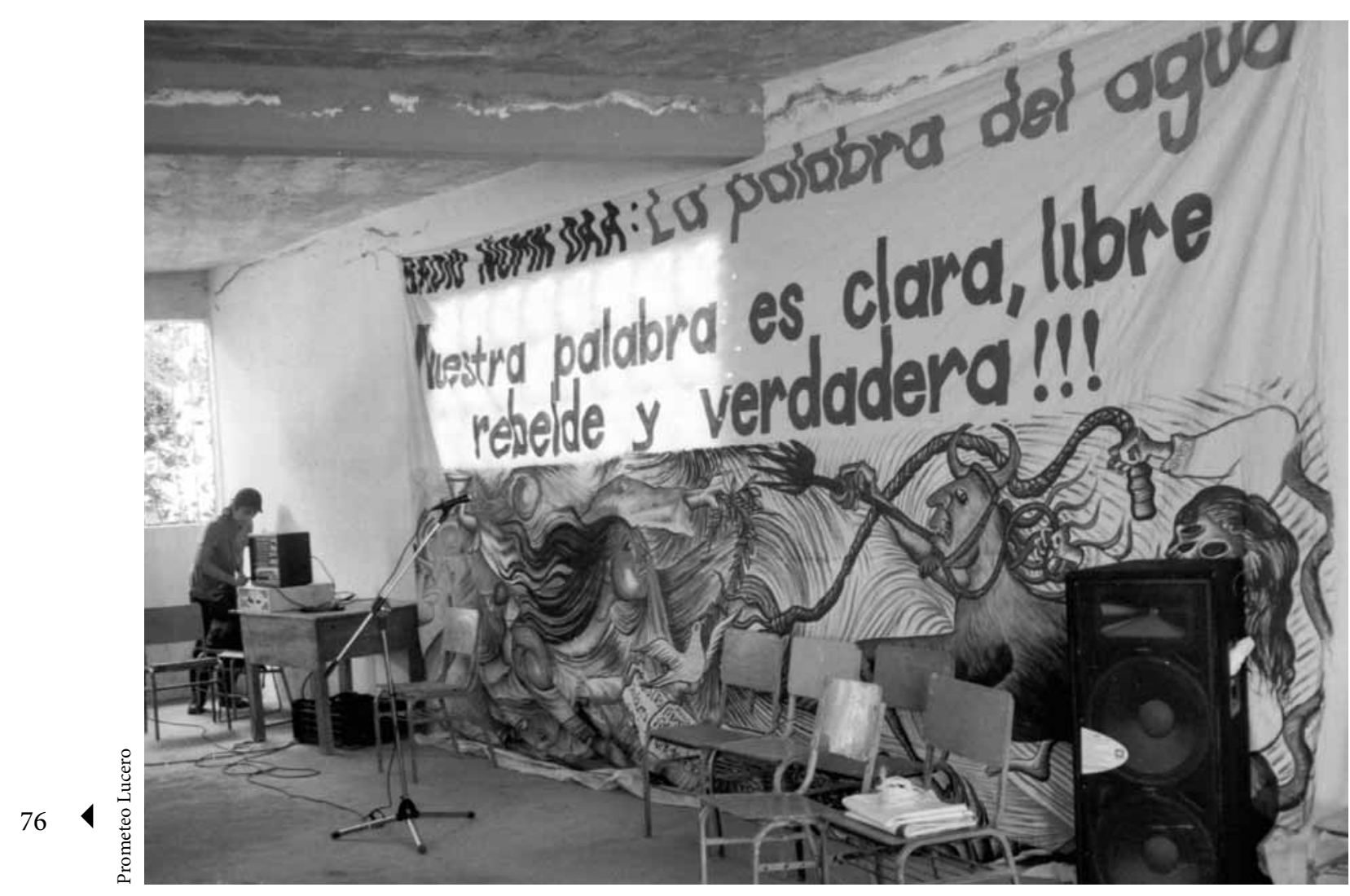

Aniversario de Radio Ñomndaa en el pueblo de Suljáá (Xochistlahuaca), Guerrero, 2010.

como pueblos y conservar la tierra y el medio ambiente en que viven. Esta lucha no es entre fuerzas externas que se disputan territorio y naturaleza. A primera vista, puede parecer que efectivamente es un conflicto entre un invasor -o un grupo de invasores-y los pobladores, y que este invasor, a título individual, por su propia voluntad, quiere apropiarse de los bienes de comunidades que ha encontrado a su paso o que se encuentran en su ruta de dominación, pero no es así. En este caso, el invasor es parte de políticas y prácticas de poder de carácter global, como son las políticas del capital, y los sujetos colectivos no se enfrentan a las empresas, sino a la fuerza del capital y sus distintas formas de ejercicio del poder, las cuales van desde el convencimiento y la negociación hasta el ejercicio de la violencia "legítima" (Weber, 1964) y del terror de parte del Estado, o el ejercicio de la violencia irregular de las propias empresas. No es un encuentro en el tiempo y en el espacio, sino una determinada forma de relación.

No está de más recordar que las formas de relación con la población campesina e indígena anteriores a la que ahora prevalece tampoco han sido de externalidad. La forma Estado y la forma mercado implican ya relaciones mediadas por el capital. En la relación que nos ocupa, el tiempo y el espacio están definidos por la acumulación de capital, por lo menos en sus aspectos dominantes. Por eso es posible interpretar la lucha colectiva contra dichas políticas como proceso de negación de los de abajo al tipo de relación que el capital trata de imponer, es decir, como resistencia que surge de una relación antagónica. Esto se presenta de manera clara en la imagen 
del capital que aparece en la narración de dos miembros del Copudever: ${ }^{11}$

Estando el río libre hay libertad para tomar agua de riego, para el ganado, se puede pescar libremente para el sustento de la familia y de la comunidad, y desgraciadamente cuando se dan las presas todo se privatiza, porque ya hay restricción, ya no se puede llegar libremente, ni arrimarse, porque te corren, ya habría un control, tendríamos que pagar. La pesca ya no va a ser libre, y ni pescado habría porque el río se seca y ya no hay producción. Por eso hay que cuidarlo, la grava, la arena, la piedra, la madera. Ahora no hay problema, porque si uno quiere hacer un mueble, corta un árbol y ya. Pero hay riesgo de que todo desaparezca para la comunidad, y por eso resistimos, porque ese proyecto acabaría con todo (entrevista a Jaime Jiménez Ruiz y Estela Chávez).

En términos objetivos, la lucha entre el capital y dichos sujetos colectivos es una lucha de clases. Sin embargo, plantea cambios significativos que tienen que ver directamente con una subjetividad que sugiere, anuncia, una nueva constelación conceptual. ${ }^{12}$ Uno de los cambios experimentados se relaciona con la naturaleza y el trabajo. Walter Benjamin (2007), en la soledad de su circunstancia, había planteado que la idea de trabajo del marxismo vulgar era un concepto "corrupto" de gravísimas implicaciones políticas. Si bien se refería a la socialdemocracia de su tiempo, la crítica tiene una significación más amplia y actual. Dice:

Esta concepción del marxismo vulgar sobre lo que es el trabajo no se detiene demasiado en la cuestión acerca del efecto que el producto del trabajo ejerce

\footnotetext{
${ }^{11}$ El Copudever es una organización integrada desde 2006 por indígenas y campesinos de los municipios de Santiago Jamiltepec, Tataltepec de Valdés, Santiago Ixtayutla, Santa Cruz Zenzontepec, Santiago Tetepec y Villa de Tututepec, en la costa oaxaqueña, contra el Proyecto de Aprovechamiento Hidráulico de Usos Múltiples Paso de la Reina, impulsado por la Comisión Federal de Electricidad, sobre el río Verde. La construcción de esta presa afectaría directamente 3100 hectáreas en seis municipios y más de 40 localidades.

${ }^{12}$ Para la idea de "constelación conceptual" véase Adorno (1975).
}

sobre los trabajadores cuando éstos no pueden disponer de él. Sólo está dispuesta a percibir los progresos del dominio sobre la naturaleza, no los retrocesos de la sociedad. Muestra ya los rasgos tecnocráticos con que nos toparemos más tarde en el fascismo (Benjamin, 2007: Tesis XI, pp. 31-32).

Una idea de trabajo atada servilmente a la idea de progreso. En consecuencia, rinde culto a la técnica y a la explotación de la naturaleza, y muestra los rasgos de la dominación tecnocrática. Dicha idea de trabajo acompañó a las luchas obreras por el mejoramiento de su situación salarial y contribuyó a fomentar cierto conformismo político dentro de las clases trabajadoras, como dice Benjamin (Tesis XI). De otra parte, esa noción "corrupta" se tradujo en políticas de centralización burocrática compulsiva del trabajo en los países del llamado socialismo real. En general, la explotación de la naturaleza y su uso instrumental como parte de un trabajo cuyo metabolismo la transforma en cosa - trabajo abstracto- está en la base de la crisis actual (Holloway, 2010; Postone, 2006).

En los movimientos a los que nos hemos referido hay una crítica a esa noción de trabajo - unas veces implícita; otras, explícita- y tiene que ver con la forma de relación con la naturaleza, antagónica a la capitalista. Se ha planteado que para dichos sujetos la tierra y los recursos naturales no son objetos ni mercancías, para ellos el uso de la tierra, los bosques y los ríos presupone su cuidado. Sin embargo, ese tipo de relación no glorifica el conocimiento tradicional en un repliegue conservador hacia la comunidad, más bien abre las posibilidades de un diálogo con un tipo de conocimiento científico alternativo a la forma instrumental de apropiación de la naturaleza, propia del trabajo abstracto en el capitalismo. ${ }^{13}$

Pero la crítica fundamental a las prácticas productivas cosificadoras de la naturaleza viene de la

\footnotetext{
${ }^{13}$ Por eso, no está de más subrayar que la concepción ahistórica de las ciencias - naturales y físico-matemáticas- ha sido una puerta de entrada para el positivismo y la idea de progreso en la concepción de la sociedad, incluyendo al marxismo tradicional. Véase Sohn (2001).
} 
noción de sujeto colectivo. En un proceso difícil y contradictorio, estos movimientos han forjado una conciencia en que la crítica de las relaciones instrumentales con la naturaleza es parte de la forma de lo colectivo. Para ellos, tierra, agua, aire, no son formas de mundo radicalmente separadas de la sociedad sino que conforman una unidad en la diferencia, son parte de la colectividad y la colectividad es parte de esas formas de mundo. Esa dialéctica es una exteriorización de las relaciones sociales que se estructuran al interior de la comunidad, donde la experiencia de lucha ha revalorizado tradiciones en clave de rechazo a las relaciones instrumentales entre los miembros de la comunidad, lo cual se expresa en las relaciones de representación en el colectivo social. Por ejemplo, desde que el CECOP se constituyó para luchar contra la construcción de la presa en su territorio, se han cuestionado y trastocado las relaciones de representación, los modos de articulación y asociación, así como las capacidades de deliberación y resolución de los asuntos comunes.

Los comisariados son nuestros representantes, pero ellos no deciden, decide el pueblo. De todo esto hemos ido creando conciencia. Muchas veces el pueblo estaba confundido, que el comisariado podía decidir. Ahora no, el pueblo, la asamblea es la que decide (entrevista a Felipe Flores).

En esa forma horizontal de colectivización la experiencia zapatista en general y la experiencia autonómica en particular han sido paradigmáticas. Se puede afirmar, en ese sentido, que la idea de autonomía zapatista ha potenciado las tradiciones de autogobierno de los movimientos socioambientales estudiados. Entre otras cosas, porque el zapatismo creó un nuevo horizonte legítimo de la política como autonomía de los de "abajo a la izquierda", el cual es como un espejo gigantesco donde se ven y se piensan otras experiencias de autonomía. Una característica de la autonomía zapatista es que implica prácticas que son un proceso de transformación y redefinición del trabajo. El centro de la cuestión es que la comunidad no debe estar al servicio del trabajo sino el trabajo al servicio de la comunidad. Es decir, que el trabajo es entendido como un momento de la autonomía de la colectividad y de los individuos que la componen. Si la noción "corrupta" de trabajo ya mostraba los rasgos tecnocráticos de la dominación, como lo señaló Walter Benjamin, se podría decir que la noción zapatista de trabajo muestra ya ciertos rasgos de una sociedad emancipada, cuya representación no es una figura de Estado: el acento está puesto en las colectividades autoorganizadas. Por esa razón, la idea zapatista de autonomía ha iluminado las luchas sociales, en particular las de las colectividades que defienden la tierra y la naturaleza contra el despojo del capital.

Se podría suponer, sin embargo, que estos movimientos son definitivamente marginales y que no pueden alterar de manera significativa el curso del esquema político nacional. Esto sería tanto como decir que todo proceso de cambio surge de instancias que tienen una vocación de poder y hegemonía nacionales, y que los sujetos que tienen o pueden desarrollar una vocación de horizontalidad anticapitalista en espacios en apariencia marginales están condenados objetivamente a una triste condición subalterna en la periferia de ese poder nacional. Por el contrario, nosotros creemos que los grandes cambios se generan en los intersticios del abajo rebelde de la sociedad, al que pertenecen los movimientos que hemos presentado. La crisis de las formas institucionales destinadas a procesar y regular el antagonismo de clase, como todo el aparato estatal de la democracia representativa, es importante para pensar las condiciones necesarias de un cambio radical en el rumbo del país. Pero la crisis de las formas institucionales se genera principalmente por el movimiento de la rebeldía de los de abajo, el cual se fragua y se expresa de modos diversos. No hay que olvidar que estos movimientos atacan puntos centrales del modelo de acumulación actual, como se ha visto.

Uno de los aspectos más relevantes de esas rebeldías es el horizonte alternativo de visibilidad que pueden llegar a producir y sin el cual no hay 
posibilidad de romper el continuum de la dominación, para citar de nuevo a Benjamin (2007). El llamado "núcleo de buen sentido" que da la experiencia de lucha, para retomar la idea de Gramsci que introdujimos y acotamos al principio, no puede desplegarse de manera que produzca una forma radical coherente sin un horizonte que anticipe ciertos rasgos de otra sociedad como parte del proceso de negación de la sociedad actual.

Precisamente, algunos de esos rasgos prefigurativos son los que hemos querido destacar en este breve escrito. Rasgos que son parte de la memoria colectiva, entendida como un componente fundamental de la subjetividad de los actores en lucha que permite procesar, seleccionar, condensar, fijar y transmitir la experiencia en formas coherentes de rebeldía. Como hemos tratado de explicar, en la forma comunitaria de la lucha han surgido nuevos rasgos que anuncian una temporalidad anticapitalista. El sujeto comunitario de los movimientos socioambientales aquí tratados ya no ve al Estado como el único lugar al cual dirigirse para garantizar precarios márgenes de sobrevivencia en un entramado patrimonialista de dominación. Más bien, la autonomía es vista como una forma posible de existencia emancipada, para lo cual es necesario juntar muchas luchas y construir un abajo con espíritu de escisión frente al poder del capital. Por otro lado, este tipo de movimientos forma parte de una constelación de luchas que recorre el territorio nacional y que tiene manifestaciones muy parecidas en el ámbito latinoamericano, como la experiencia de luchas de carácter comunitario-popular en Bolivia, el movimiento de resistencia mapuche en Chile, el Movimiento de los Sin Tierra y el Movimiento de Afectados por las Represas en Brasil, para nombrar sólo algunas.

Habría que decir también que como parte de ese proceso se ha gestado un movimiento teórico que en gran parte viene de la crítica al marxismo ortodoxo y su idea instrumental y Estado-céntrica de la lucha de clases. Un hecho radical como el derrumbe del campo soviético no podía menos que poner en duda los cimientos teóricos de su construcción, básicamente la ideología oficial que se codificó con el marxismo-leninismo. En tales circunstancias, la búsqueda de explicaciones al fracaso soviético trajo a la luz un pasado teórico crítico que había detectado fallas fundamentales en la concepción de la lucha de clases y la revolución. Ese pasado, se podría decir, se hizo presente por la fuerza de nuevas generaciones de luchadores que están intentando dar respuestas creativas a dichos problemas y que se han nutrido de la tradición heterodoxa del marxismo y del pensamiento crítico en general, así como de las nuevas luchas sociales, en las que el zapatismo ha jugado un papel central, inspirando ideas que buscan nuevas rutas para un cambio radical. Entonces, no es aventurado plantear que este conjunto de luchas emergentes y ya establecidas, que comparten horizontes semejantes, entre ellos el de la autonomía, son parte de una nueva constelación de lucha de clases, cuyas consecuencias prácticas y teóricas están todavía por desarrollarse.

En este trabajo presentamos algunas ideas referidas a la memoria colectiva y al componente subjetivo anticapitalista de las luchas socioambientales en México, pero los temas son más variados y complejos. Por ejemplo, un asunto relacionado con la autonomía como categoría crítica es que ésta, lejos de apuntar hacia una micropolítica posmoderna o a una política inspirada en el multiculturalismo, introduce el tema de la lucha de clases desafiando la noción de clase como una suerte de totalidad homogénea, cuestión que sólo podemos apuntar en este escrito pero que es necesario trabajar. En todo caso, en esas luchas podemos percibir un movimiento potencialmente transformador de la sensibilidad y de la cultura de la izquierda. Como hemos tratado de plasmar en estas páginas, la memoria rebelde y una forma de ciencia que no se relaciona con aquélla de manera externa, ya sea para negarla o instrumentalizarla, porque ella misma es parte de la rebeldía, tienen un lugar central en este proceso. 


\section{Bibliografía}

Adorno, Theodor, 1975, Dialéctica negativa, Taurus, Madrid. Anderson, Benedict, 1993, Comunidades imaginadas. Reflexiones sobre el origen y la difusión del nacionalismo, Fondo de Cultura Económica, México.

Benjamin, Walter, 2007, Sobre el concepto de historia. Tesis $y$ fragmentos, Editorial Piedras de Papel, Buenos Aires.

Ceceña, Ana Esther, 2008, Derivas del mundo en el que caben todos los mundos, Consejo Latinoamericano de Ciencias Sociales, Siglo XXI, Buenos Aires.

— 2010, "Dominar la naturaleza o vivir bien: disyuntiva sistémica”, ponencia, Instituto de Investigaciones Económicas-Universidad Nacional Autónoma de México, México.

Gilly, Adolfo y Rhina Roux, 2009, “Capitales, tecnologías y mundos de la vida: el despojo de los cuatro elementos", en Herramienta, núm. 40, marzo, Buenos Aires.

Gramsci, Antonio, 1980, "Relaciones entre ciencia-religión-sentido común”, en Manuel Sacristán, Antonio Gramsci: antología, Siglo XXI, México.

Gutiérrez, Raquel, 2009, Los ritmos de Pachakuti, Bajo Tierra, Instituto de Ciencias Sociales y HumanidadesBenemérita Universidad Autónoma de Puebla, México.

Harvey, David, 2001, Espacios del capital: hacia una geografía crítica, Akal, Madrid.

Holloway, John, 2010, Crack Capitalism, Plutto Press, Londres.

Leff, Enrique, 2006, "La ecología política en América Latina: un campo en construcción”, en Héctor Alimonda, Los tormentos de la materia: aportes para una ecología política latinoamericana, Consejo Latinoamericano de Ciencias Sociales, Buenos Aires.

Macpherson, C. B., 1979, La teoría política del individualismo posesivo, Editorial Fontanella, Barcelona.

Martínez Alier, Juan, 2009, "Conflictos ecológicos y lenguajes de valoración”, ponencia, Ecología Política en el Capitalismo Contemporáneo, Programa Latinoamericano de Educación a Distancia, Centro Cultural de la Cooperación Floreal Gorini, Buenos Aires.
Navarro, Mina L. y Enrique Pineda, 2009, "Luchas socioambientales en América Latina y México: nuevas subjetividades y radicalidades en movimiento", en Revista Bajo el Volcán, núm. 14.

Ouviña, Hernán, 2007, "Hacia una política prefigurativa. Algunos recorridos e hipótesis en torno a la construcción del poder popular", en Omar Acha, Reflexiones sobre el poder popular, Editorial El Colectivo, Buenos Aires.

Postone, Moishe, 2006, Tiempo, trabajo y dominación social, Marcial Pons, Madrid, Barcelona.

Regalado, Jorge, en prensa, "Luchas sociales contra el despojo del territorio y los recursos naturales en Jalisco, México", México, en prensa.

Shiva, Vandana, 2006, Manifiesto para una democracia de la tierra, Paidós Ibérica, Barcelona.

Sohn Rethel, Alfred, 2001, Trabajo manual y trabajo intelectual. Crítica de la epistemología, El Viejo Topo, Barcelona.

Weber, Max, 1964, Economía y sociedad, Fondo de Cultura Económica, México.

\section{Entrevistas}

Marco Suaste (CECOP), 2008, en Memoria del Encuentro Popular sobre Agua, Energía y Alternativas Energéticas, Cacahuatepec, Guerrero, noviembre.

Rodolfo Chávez (CECOP), 2009, Chiapas, diciembre.

Jaime Jiménez Ruiz y Estela Chávez (Copudever), 2010, Paso de la Reina, VII Encuentro del Movimiento de Afectados por las Presas y en Defensa de los Ríos (Mapder), Oaxaca, febrero.

Felipe Flores (CECOP), 2010, ciudad de México, mayo. Graciela y Enrique Enciso (Agrupación Un Salto de Vida), 2010, Jalisco, febrero.

David Valtierra (Radio Nomndaa), 2010, Guerrero, diciembre. 